\title{
Estimation of bulk permittivity of the Moon's surface using Lunar Radar Sounder on-board Selenological and Engineering Explorer
}

\author{
Keigo Hongo ${ }^{1}$, Hiroaki Toh ${ }^{1 *}$ (i) and Atsushi Kumamoto ${ }^{2}$
}

\begin{abstract}
Site-dependent bulk permittivities of the lunar uppermost media with thicknesses of tens to hundreds meters were estimated based on the data from Lunar Radar Sounder onboard the Selenological and Engineering Explorer (SELENE). It succeeded in sounding almost all over the Moon's surface in a frequency range around $5 \mathrm{MHz}$ to detect subsurface reflectors beneath several lunar maria. However, it is necessary to estimate the permittivity of the surface regolith of the Moon in order to determine the actual depths to those reflectors instead of apparent depths assuming a speed of light in the vacuum. In this study, we determined site-dependent bulk permittivities by two-layer models consisting of a surface regolith layer over a half-space with uniform, but different physical properties from the layer above. Those models consider the electrical conductivity as well as the permittivity, whose trade-off was resolved by utilizing the correlation between iron-titanium content and measured physical properties of lunar rock samples. Distribution of the iron-titanium content on the Moon's surface had already been derived by spectroscopic observation from SELENE as well. Four lunar maria, Mare Serenitatis, Oceanus Procellarum, Mare Imbrium, and Mare Crisium, were selected as regions of evident reflectors, where we estimated the following four physical properties of each layer, i.e., bulk permittivity, porosity, loss tangent and electrical conductivity to conclude the actual depths of the reflectors are approximately $200 \mathrm{~m}$ on average. The bulk permittivity ranges from 2.96 at Mare Imbrium to 6.37 at Oceanus Procellarum, whereas the porosity takes the values between 1.8 and $41.1 \%$ in the respective maria. It was found that although the bulk permittivity of the four lunar maria differs from a mare to a mare, it shows a good correlation with their composition, viz., their iron-titanium content.
\end{abstract}

Keywords: Selenological and engineering explorer, Frequency-modulated continuous wave radar, Bulk permittivity, Loss tangent, Subsurface reflectors

\section{Introduction}

The first exploration of the Moon's subsurface structure was conducted by Apollo Lunar Sounder Experiment (ALSE) (Porcello et al. 1974) aboard Apollo 17 launched in 1972. ALSE observed the reflected echoes of the radar transmitted from the mother ship orbiting above the lunar equator. Objectives of ALSE were subsurface exploration of the Moon and profiling/imaging of its surface.

\footnotetext{
*Correspondence: tou.hiroaki.7u@kyoto-u.ac.jp

${ }^{1}$ Division of Earth and Planetary Sciences, Graduate School of Science,

Kyoto University, Kyoto, Japan

Full list of author information is available at the end of the article
}

To achieve those, ALSE was operated at a few frequency bands of 5, 15 and $150 \mathrm{MHz}$ with linearly increasing frequency (chirp signals) so as to improve the penetration depth and the ranging resolution. The largest penetration depth of approximately $1.3 \mathrm{~km}$ was achieved by the $5-\mathrm{MHz}$ operation with an apparent resolution of $300 \mathrm{~m}$. However, both the depth and the resolution are dependent on the permittivity inside the Moon. ALSE detected horizontal reflectors at an apparent depth of about $1 \mathrm{~km}$ beneath Mare Serenitatis and Mare Crisium (Peeples et al. 1978; Phillips et al. 1973a, b) by its limited observation from several orbits. 
Lunar Radar Sounder (LRS) is a frequency-modulated continuous wave radar (Ono and Oya 2000) equipped with SELenological and ENgineering Explorer (SELENE) launched in 2007 (Kato et al. 2008). Because it was the first Japanese spacecraft to the Moon, it also has a Japanese name of KAGUYA coined after a princess believed to live on the Moon. Like ALSE, LRS also aimed at subsurface exploration of the Moon using high-frequency chirp signals ranging from 4 through $6 \mathrm{MHz}$. Major differences, however, from ALSE were its deeper penetration depth and finer resolution, which were $5 \mathrm{~km}$ and $75 \mathrm{~m}$ in vacuum and were much better than those of ALSE (Ono and Oya 2000; Ono et al. 2008). Spatial coverage of SELENE was excellent in the sense that almost all of the Moon's surface including the far side was covered by the sounder observation from SELENE's polar orbits with an averaged altitude of $100 \mathrm{~km}$ above the Moon's surface. The total duration of the sounder observation summed up to as long as 100 days. As a result, Ono et al. (2009) reported presence of subsurface reflectors beneath several lunar maria. Apparent depths to those reflectors were a few hundreds of meters but we need to know the permittivity beneath the Moon's surface for conversion of those values to the true depths. Furthermore, quantitative delineation of the Moon's subsurface structure such as the true depths to the reflectors leads to understanding the origin and evolution of our Moon. It, therefore, is very important to analyze the LRS data of SELENE, which provided unprecedented radar sounding in terms of both quality and quantity.

Another example of planetary radar sounding can be found in Mars. Mars Advanced Radar for Subsurface and Ionosphere Sounding on-board Mars Express in 2003 detected presence and quantity of water ice accumulated in the Mars's polar cap (Picardi et al. 2005; Plaut et al. 2007). Presence of water ice on Mars was further confirmed by Shallow Radar Sounder aboard Mars Reconnaissance Orbiter in 2005. Karlsson et al. (2015) found the water ice even in Mars's mid-latitudes, while Holt et al. (2010) revealed a complex sedimentary structure beneath the Mars's northern polar cap. These new findings are expected to elucidate the past Mars's climate and/or traces of paleo-oceans on Mars.

On the other hand, JUpiter ICy moon Explorer (JUICE) by European Space Agency (ESA) is planned to launch in 2022. According to ESA (2014), Radar of Icy Moon Exploration aboard JUICE is going to conduct radar sounding of three icy Galilean satellites, i.e., Europa, Ganymede and Calisto so as to explore the subsurface structures, ice, water and their composition. Those sounding will be of great help for detecting subsurface oceans of those moons, which may constitute cradles for extraterrestrial lives.

Unlike the sample return missions, the past and future radar sounding from spacecraft illustrates efficiency, certainty and wide spatial coverage of planetary-scale exploration by radar sounders. In order to improve applicability of radar sounding, the LRS data have been combined with model calculation of electromagnetic (EM) wave propagation (Ono et al. 2009; Bando et al. 2015) and data by laser altimetry to estimate the thickness of the regolith layer on top of the Moon as well as to improve the ranging resolution of LRS itself by application of data processing techniques originally developed for synthetic aperture radars (Kobayashi and Ono 2007; Kobayashi et al. 2012).

Ono et al. (2009) argued the possibility of detection of the subsurface regolith layer sandwiched between basaltic layers above and below as reflectors. This is because the reflectors are detected at shallower depths than the thickness of the basaltic layers estimated by crater analyses in lunar maria (De Hon 1979; Williams and Zuber 1998). Oshigami et al. (2009) further claimed that the correlation between the surface age and detection rate of the reflectors means thicker regolith layers in older regions.

Another correlation, which is negative though, between the detection rate and surface distribution of ilmenite suggests that metals such as titanium may prevent penetration of radar pulses to interfere the reflector detection (Pommerol et al. 2010; Olhoeft and Strangway 1975; Carrier et al. 1991; Shkuratov and Bondarenko 2001). The composition of the Moon's surface was revealed by spectroscopic studies of SELENE data. This means that both permittivity and loss tangent are important physical properties of the lunar surface, because the former determines the speed of light in the medium while the latter is defined as the ratio of the conduction current to the displacement current and plays a role in attenuation of the radar pulses. Analyses of lunar rock samples strongly imply the correlation between the loss tangent and the iron-titanium content, whereas the permittivity does not show significant dependence on rock composition. It has, in turn, a strong correlation with rock density (Olhoeft and Strangway 1975; Carrier et al. 1991; Shkuratov and Bondarenko 2001). The different dependence of physical properties of the Moon's surface suggests regional dependence of those properties, and thus implies necessity of determination of those properties from place to place.

Porosity is another factor of consideration here. Effects of bulk porosity are inevitably included in the results of radar sounding in a form of bulk density. If we can also estimate porosity from our LRS data, it can be another important database, since Rust et al. (1999) pointed out that porosity is indicative of volcanism/tectonics of the Moon in the past.

Ishiyama et al. (2013) performed combined analyses of the delay of echoes from the subsurface reflectors and 
the depth of subsurface reflectors excavated at the impact craters based on data from LRS, Multiband Imager (MI) and Terrain Camera (TC) onboard the SELENE spacecraft, and determined the speed of the radar wave in uppermost layers in several maria. Based on the speed, they also estimated bulk permittivity and porosity. The estimated bulk permittivities were between 1.6 and 14.0 in Mare Serenitatis, and between 1.3 and 5.1 in Oceanus Procellarum. They also pointed out that the estimated porosity, up to about $80 \%$, was much larger than that of Apollo soil samples, and discussed possible contributions of intrinsic voids of lava and impact-induced cracks.

In this study, we aim for estimation of the relative permittivity of the Moon's surface by comparison of echo intensities from the surface and subsurface reflector. We will approximate the Moon by two-layer models with different permittivities and electrical conductivities in each layer and determine those model parameters by calculation of EM wave propagation according to the radar range equation. In the course of estimation, we newly introduce correlation between the electrical conductivity and the iron-titanium content to resolve the non-uniqueness appeared in previous studies. This study will also provide spatial dependence of the true depths to the detected reflectors, which may lead to better understanding of the Moon's subsurface structures. Furthermore, those true depths can be applied to estimation of erupted lava volumes, which are useful in unraveling the Moon's volcanism in the past. Finally, the estimated loss tangent and porosity contribute to the understandings of the Moon's evolution and thermal history as well.

\section{Data of Lunar Radar Sounder}

A pair of mutually orthogonal 30-m dipole antennas was used for LRS. The pulse width $(T)$, sweep rate $(\dot{f})$ and output power $\left(P_{\mathrm{t}}\right)$ of the transmitted chirp signals were $200 \mu \mathrm{s}$, $10 \mathrm{kHz} / \mu \mathrm{s}$ and $800 \mathrm{~W}$, respectively. Each pulse was further shaped by a sinusoidal wave to minimize sidelobe effects at the time of Fast Fourier Transform (FFT) and is given by:

$$
V_{\mathrm{TX}}(t)=V_{\mathrm{TX} 0} \sin \left(\pi \frac{t}{T}\right) \sin \left(\int_{0}^{t} 2 \pi\left(f_{0}+\dot{f} t^{\prime}\right) \mathrm{d} t^{\prime}\right),
$$

where $V_{\mathrm{TX} 0}$ is the amplitude of the transmitted pulse and $f_{0}=4 \mathrm{MHz}$.

$$
\begin{aligned}
& V_{\mathrm{RX}}(t) V_{\mathrm{LO}}(t) \\
& =V_{\mathrm{RX} 0} V_{\mathrm{LO} 0} \sin \left(\pi \frac{t-\tau_{\mathrm{RX}}}{T}\right) \sin \left(\int_{0}^{t-\tau_{\mathrm{RX}}} 2 \pi\left(f_{0}+\dot{f} t^{\prime}\right) \mathrm{d} t^{\prime}\right) \sin \left(\int_{0}^{t-\tau_{\mathrm{LO}}} 2 \pi\left(f_{0}+\dot{f} t^{\prime}\right) \mathrm{d} t^{\prime}\right) \\
& =V_{R X 0} V_{L O 0} \sin \left(\pi \frac{t-\tau_{\mathrm{RX}}}{T}\right) \sin \left[2 \pi\left\{f_{0}\left(t-\tau_{\mathrm{RX}}\right)+\frac{1}{2} \dot{f}\left(t-\tau_{\mathrm{RX}}\right)^{2}\right\}\right] \sin \left[2 \pi\left\{f_{0}\left(t-\tau_{\mathrm{LO}}\right)+\frac{1}{2} \dot{f}\left(t-\tau_{\mathrm{LO}}\right)^{2}\right\}\right] .
\end{aligned}
$$

In general, radars are associated with a trade-off between the penetration depth, which is a function of the output power, and the ranging resolution, which is a function of the pulse width. However, the pulse compression technique using chirp signals gives us a radar with a large output power and a narrow pulse width at the same time, which improves both the penetration depth and the ranging resolution. In the case of LRS, they are $5 \mathrm{~km}$ and $75 \mathrm{~m}$ in vacuum as mentioned before, but they are also dependent on both the permittivity and the loss tangent beneath the Moon's surface. The LRS operation throughout the mission was done by $20-\mathrm{Hz}$ transmission for 72 days, while it was operated with a transmission rate of $2.5 \mathrm{~Hz}$ for the remaining 27 days. The LRS data are now open to the public at: http://darts.isas.jaxa.jp/planet/pdap/selene/, and all the data used in this study were downloaded from this Japan Aerospace Exploration Agency website.

\section{A-scope data}

Received echoes of LRS are not original waveforms of the reflected echoes themselves, but resampled waveforms multiplied by a local signal, which were further transferred to the Earth from the spacecraft. The observed data, therefore, are different from the original waveforms of the reflected echoes.

Specifically, let the original waveform be:

$$
V_{\mathrm{RX}}(t)=V_{\mathrm{RX} 0} \sin \left(\pi \frac{t-\tau_{\mathrm{RX}}}{T}\right) \sin \left(\int_{0}^{t-\tau_{\mathrm{RX}}} 2 \pi\left(f_{0}+\dot{f} t^{\prime}\right) \mathrm{d} t^{\prime}\right),
$$

where $V_{\mathrm{RX} 0}$ is the amplitude of the reflected echo and $\tau_{\mathrm{RX}}$ is a two-way travel time of the echo, by which the apparent depth to the reflector, $d_{\mathrm{A}}$, can be given by:

$$
d_{\mathrm{A}}=\frac{c_{0} \tau_{\mathrm{RX}}}{2},
$$

where $c_{0}$ is the speed of light in vacuum. In chirp radars, the received echoes are further mixed with an inherent local signal of the receiver typically given by the following formula:

$$
V_{\mathrm{LO}}(t)=V_{\mathrm{LO} 0} \sin \left(\int_{0}^{t-\tau_{\mathrm{LO}}} 2 \pi\left(f_{0}+\dot{f} t^{\prime}\right) \mathrm{d} t^{\prime}\right),
$$

where $V_{\mathrm{LO} 0}$ is the amplitude of the local signal and $V_{\mathrm{LO}}$ is the time of the mixing onset. The waveform after mixing becomes: 
Using a formula for the trigonometric functions, Eq. (5) can be further modified into a sum of the high-frequency part and the low-frequency part as:
Equation (6) is then low-pass filtered with a cut-off frequency of $2 \mathrm{MHz}$ to eliminate the first term in the righthand side (R.H.S.) and resampled for 2048 points with a

$$
\begin{aligned}
V_{\mathrm{RX}}(t) V_{\mathrm{LO}}(t)= & -\frac{1}{2} V_{\mathrm{RX} 0} V_{\mathrm{LO} 0} \sin \left(\pi \frac{t-\tau_{\mathrm{RX}}}{T}\right)\left(\operatorname { c o s } \left[2 \pi \left\{f_{0}\left(2 t-\tau_{\mathrm{RX}}-\tau_{\mathrm{LO}}\right)\right.\right.\right. \\
& \left.\left.+\frac{1}{2} \dot{f}\left(2 t^{2}+\tau_{\mathrm{RX}}^{2}-2\left(\tau_{\mathrm{RX}}+\tau_{\mathrm{LO}}\right) t+\tau_{\mathrm{LO}}^{2}\right)\right\}\right] \\
& \left.-\cos \left[2 \pi\left\{\dot{f}\left(\tau_{\mathrm{RX}}-\tau_{\mathrm{LO}}\right) t+f_{0}\left(\tau_{\mathrm{RX}}-\tau_{\mathrm{LO}}\right)-\frac{1}{2} \dot{f}\left(\tau_{\mathrm{RX}}^{2}-\tau_{\mathrm{LO}}^{2}\right)\right\}\right]\right) .
\end{aligned}
$$

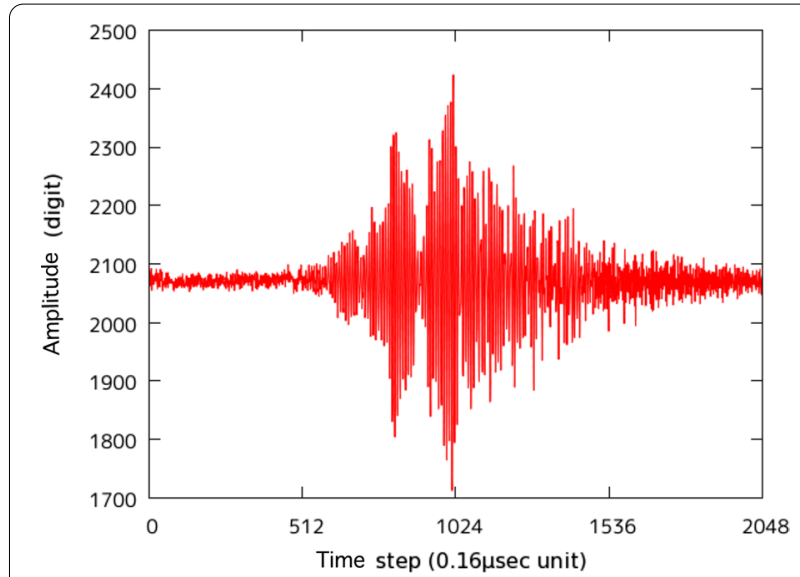

Fig. 1 An example of received waveforms. This 327.68- $\mu$ s-long time-series of a reflected echo was received at 00:57:15.181 UTC on May 4, 2008 when SELENE was flying over Mare Imbrium, i.e., $\left(40.226 \mathrm{~N}^{\circ}, 345.304 \mathrm{E}^{\circ}\right)$ in the selenographic coordinate. It is filtered and resampled as described in the text sampling frequency of 6.25 MHz. Figure 1 shows a sample plot of thus processed and transferred to the Earth.

Although filtered and resampled, the waveforms of the reflected echoes preserve the information of the twoway travel times in the form of frequency. Namely, if one makes Fourier transforms of the echoes and finds specific frequencies, $f_{\mathrm{IF}} \mathrm{s}$, for each peak reflection, then the following relation holds:

$$
f_{\mathrm{IF}}=\dot{f}\left(\tau_{\mathrm{RX}}-\tau_{\mathrm{LO}}\right)
$$

Equations (3) and (7) are combined to give:

$$
d_{\mathrm{A}}=\frac{c_{0} \tau_{\mathrm{RX}}}{2}=\frac{c_{0} \tau_{\mathrm{LO}}}{2}+\frac{c_{0} f_{\mathrm{IF}}}{2 \dot{f}} .
$$

The first term on R.H.S. of Eq. (8) is called the 'altitude origin for ranging' and recorded in the LRS data together with the received waveform itself, the time stamp, the selenographic latitude/longitude and the spacecraft's altitude. Figure 2a shows Fourier transforms of the reflected echo shown in Fig. 1. Plots of this kind are called
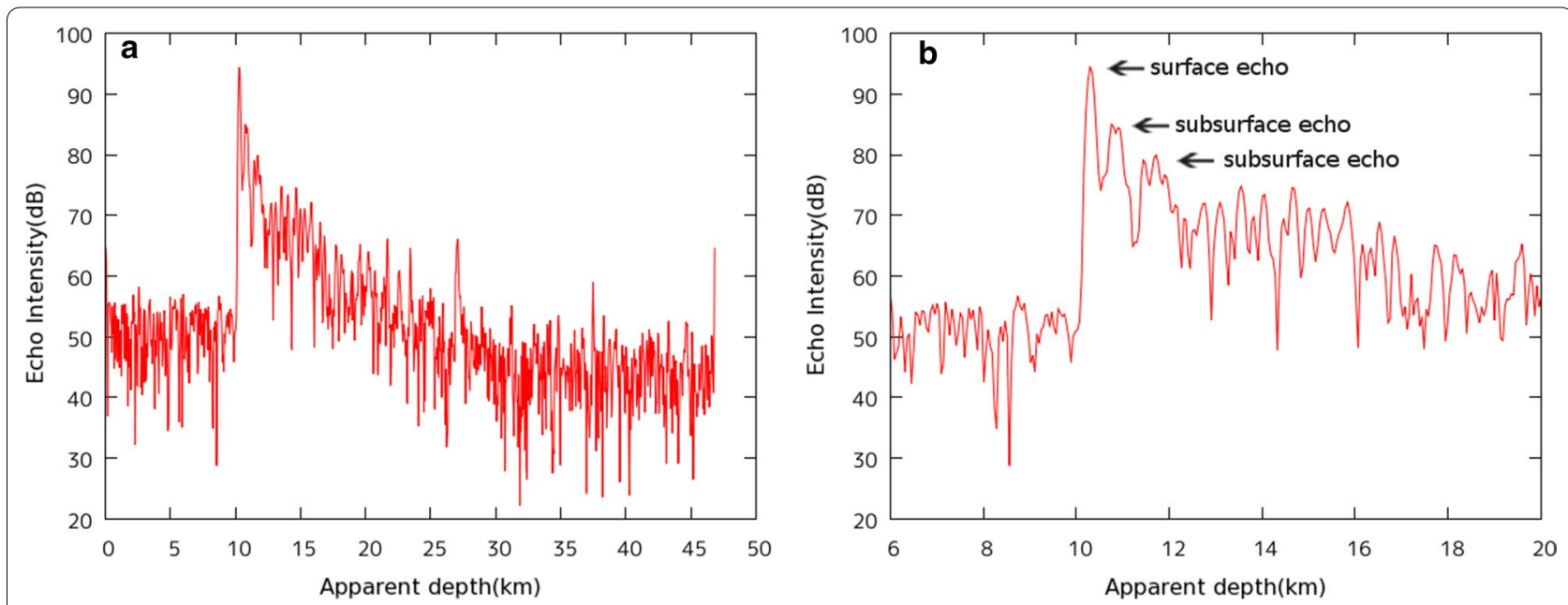

Fig. 2 a A-scope of the reflected echo of Fig. 1. We used the 2 nd term of Eq. (8) for $x$-axis instead of $d_{A}$. $\mathbf{b}$ A zoom-in plot of $\mathbf{a}$. The first three reflections including the Moon's surface are clearly seen 
'A-scope'. In Fig. 2b, three echoes are evident, one is from the Moon's surface and the other two from the subsurface reflectors.

\section{B-scan data}

B-scan is a sort of dynamic spectrum using A-scope with echo intensity in color, and is called 'radargram,' a pseudo-section of the Moon's subsurface structure. Figure 3a shows a B-scan image over Mare Imbrium. The height of the steps seen on the Moon's surface is approximately $75 \mathrm{~m}$, which is in good harmony with the ranging resolution of LRS in vacuum.

Reflected echoes do not always come from the nadir direction. If there is significant undulation of the Moon's surface, the subsurface reflectors are possibly masked by strong reflected echoes on the surface. Figure $3 \mathrm{~b}$ shows a typical example of the surface echoes, which have clear parabolic shapes because the distance between the spacecraft and the reflection points on the Moon's surface can vary with time as the spacecraft maneuvers along its orbit.

Taking running means on the B-scan images is known to give a better protection against the surface echoes (Ono et al. 2010), provided that the subsurface reflectors are horizontal. It is also desirable to compare the running means of adjacent orbits so as to confirm the echoes coming from not 'surface' but 'subsurface. Figure 3c shows a B-scan image by taking a running mean of successive 21 raw B-scan images (Ono et al. 2010). It is noteworthy that the continuity of the subsurface reflectors is much clearer than Fig. 3a.

\section{Methods}

\section{Two-layer model}

Because the regions with two subsurface reflectors like the one shown in Fig. 3c were very limited, we decided to model the majority of the LRS data by two layers, which the transmitted waves entered normal to the surface. Figure 4 shows a schematic diagram of the assumed model. Using the radar range equation (e.g., Phillips et al. 1973a), the reflected powers, $P_{\mathrm{rs}}$ and $P_{\mathrm{rss}}$, are, respectively, given by:

$$
P_{\mathrm{rs}}\left(\varepsilon_{1}\right)=\frac{P_{t} G^{2} \lambda^{2}}{4(4 \pi R)^{2}} r_{01},
$$

and

$$
P_{\mathrm{rss}}\left(\varepsilon_{1}, \varepsilon_{2}, \sigma_{1}\right)=\frac{P_{t} G^{2} \lambda^{2}}{4\left[4 \pi\left(R+R_{\mathrm{D}}\right)\right]^{2}} e^{-2 \omega \frac{R_{\mathrm{D}}}{c_{1}} \tan \delta_{1}} t_{01} r_{12} t_{10},
$$

where $G, \lambda, \omega, \tan \delta_{1}$, and $R_{\mathrm{D}}$ are the gain of the antenna, the wavelength and angular frequency of the transmitted wave, the loss tangent of the first layer and the true thickness of the first layer, respectively. SELENE transmitted a radar pulse every 0.05 (or 0.4) second with an output power of $P_{\mathrm{t}}[\mathrm{W}] . c_{1}$ is the speed of light in the first layer and given by:

$$
c_{1}=\frac{1}{\sqrt{\varepsilon_{1} \varepsilon_{0} \mu_{0}}}=\frac{c_{0}}{\sqrt{\varepsilon_{1}}},
$$

where $\varepsilon_{0}$ and $\mu_{0}$ are the permittivity and magnetic permeability in vacuum, respectively. The loss tangent in the first layer can be written by:

$$
\tan \delta_{1}=\frac{\sigma_{1}}{\omega \varepsilon_{0} \varepsilon_{1}},
$$

as well. $r_{i j}$ and $t_{i j}(i, j=0,1,2)$ denote the reflection and transmission coefficients at each interface and satisfy the following relation according to the Fresnel equations:

$$
\begin{aligned}
& t_{01}=t_{10}=\frac{4 \sqrt{\varepsilon_{1}}}{\left(1+\sqrt{\varepsilon_{1}}\right)^{2}}, \\
& r_{01}=\left(\frac{1-\sqrt{\varepsilon_{1}}}{1+\sqrt{\varepsilon_{1}}}\right)^{2}, \\
& r_{12}=\left(\frac{\sqrt{\varepsilon_{1}}-\sqrt{\varepsilon_{2}}}{\sqrt{\varepsilon_{1}}+\sqrt{\varepsilon_{2}}}\right)^{2} .
\end{aligned}
$$

Equation (15) allows solutions of both $\varepsilon_{1}>\varepsilon_{2}$ and $\varepsilon_{1}<\varepsilon_{2}$. However, if one takes $\varepsilon_{1}>\varepsilon_{2}$, it yields $1<\varepsilon_{2}<2$, which is incompatible with the results of the Moon rock analyses (e.g., Olhoeft and Strangway 1975). It, therefore, is assumed $\varepsilon_{1}<\varepsilon_{2}$ throughout this study. As for other parameters such as $R$ [m], refer to Fig. 4 and its caption.

\section{Correlation among physical properties}

The previous analyses of the lunar rock samples (Shkuratov and Bondarenko 2001; Olhoeft and Strangway 1975) revealed correlation among the physical properties of the rocks such as loss tangent, density, permittivity and irontitanium content. In short, they are expressed by the following formulae:

$$
\begin{aligned}
& \tan \delta=8.8 \times 10^{-4} e^{\frac{1-p}{2}} \rho_{\text {grain }}(S)+0.085 S, \\
& \rho_{\text {grain }}(S)=0.0165 S+2.616, \\
& \varepsilon=1.919^{\rho},
\end{aligned}
$$



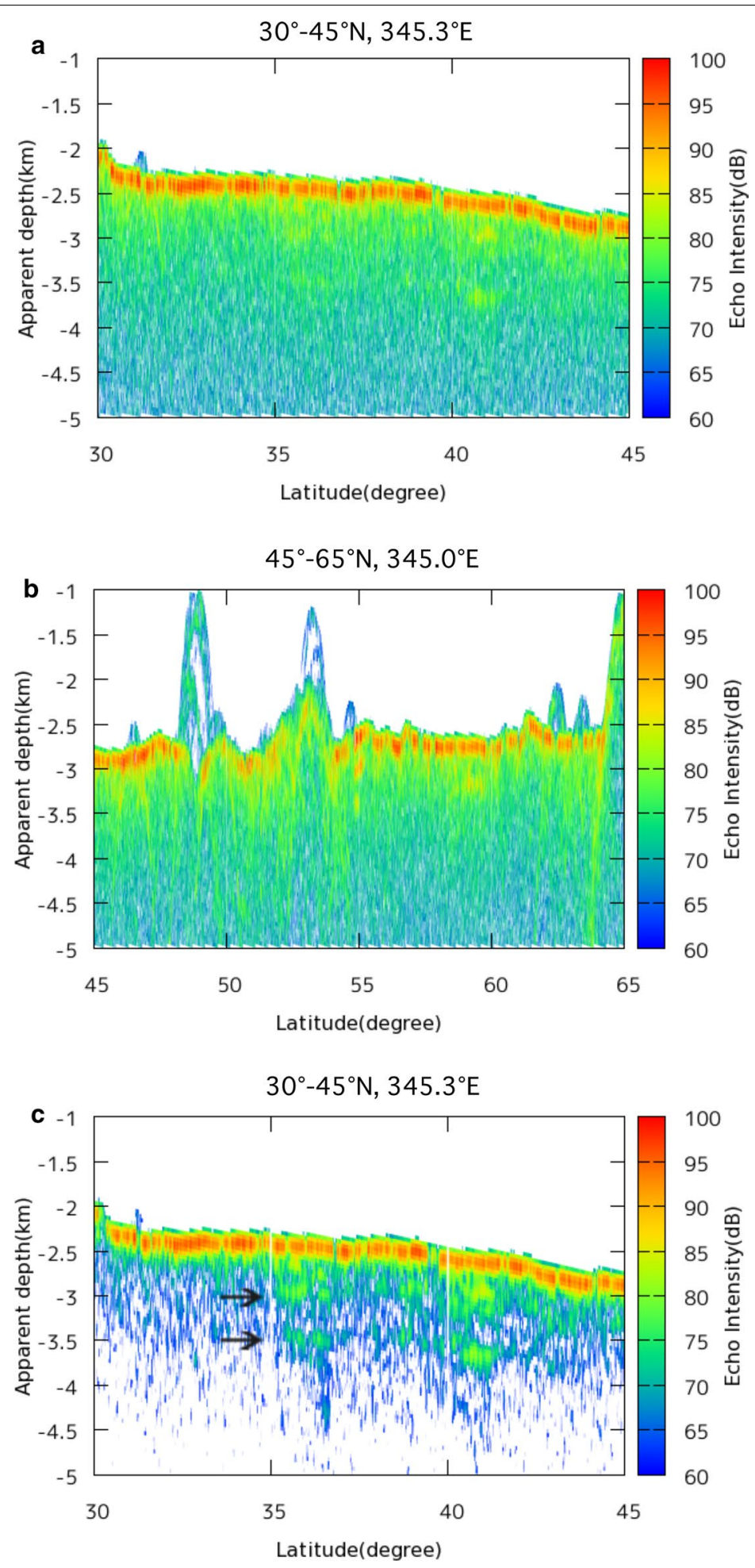

Fig. 3 a B-scan over Mare Imbrium at the selenographic longitude of $345.3 E^{\circ}$. The origin of the apparent depth is taken at the Moon's surface assuming the averaged radius of the Moon to be $1737.4 \mathrm{~km}$. b Another B-scan image at the selenographic longitude of $345.0 \mathrm{E}^{\circ}$. Several strong echoes of parabolic shape are due to craters nearby. c Taking running means highlighted the subsurface reflectors especially for those starting from the horizontal black arrows, which continue to $\sim 42 \mathrm{~N}^{\circ}$ 


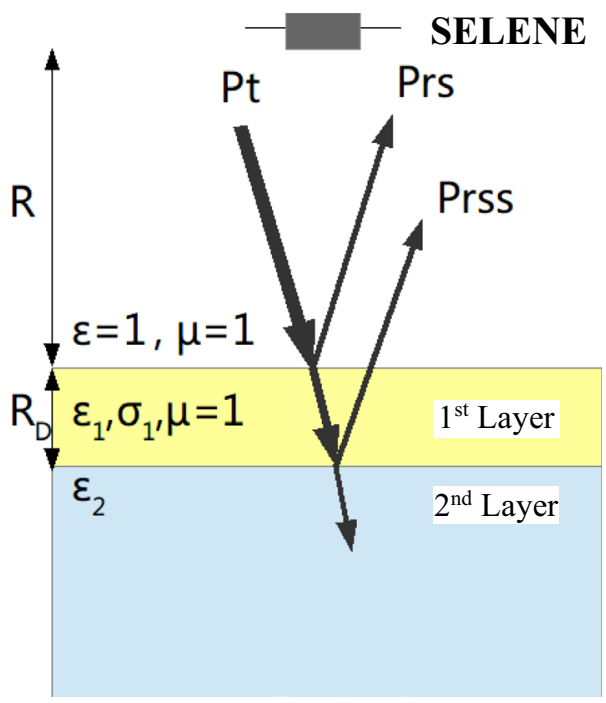

Fig. 4 The two-layer model adopted by this study. The surface and subsurface reflection are $P_{\mathrm{rs}}(\mathrm{W})$ and $P_{\mathrm{rss}}(\mathrm{W})$, respectively. $R(\mathrm{~m})$ and $R_{\mathrm{D}}(\mathrm{m})$ are, respectively, the altitude of the spacecraft and the true depth to the subsurface reflector. Both relative magnetic permeability $\mu$ and permittivity $\varepsilon$ between SELENE and the Moon's surface are assumed to be unity, while those of the 1st layer are unity and $\varepsilon_{1}$. The electrical conductivity of the 1 st layer is $\sigma_{1}$, and the bulk permittivity of the 2 nd layer is $\varepsilon_{2}$

where $S, p$ and $\rho$ are the total content of titanium and iron (wt\%), porosity and density $\left(10^{-3} \mathrm{~kg} \mathrm{~m}^{-3}\right)$, respectively. The subscript, grain, denotes the properties of the material itself. The porosity is defined by:

$$
\rho=\rho_{\text {grain }}(1-p) .
$$

The bulk estimate of permittivity in the 1st layer, $\varepsilon_{1}$, should also be compared with $\varepsilon_{\text {grain }}$.

\section{Flow of data analysis}

First, the following quantities are considered as constants: $P_{\mathrm{t}}=800 \mathrm{~W}, \lambda=0.06 \mathrm{~km}$ for the center frequency ( $5 \mathrm{MHz}$ ) for a range of $4-6 \mathrm{MHz}$ and $G=1.64$ from the theoretical value of the dipole antenna. It follows from Eqs. (9), (14) and observed $P_{\text {rs }}$ that $\varepsilon_{1}$ can be determined. Equation (18) allows us to convert thus obtained $\varepsilon_{1}$ to $\rho$.

Lawrence et al. (2002) analyzed the spectroscopic data by Lunar Prospector to yield $5^{\circ}$ by $5^{\circ}$ grid data of the surface content of iron and titanium as: http://pds-geosc iences.wustl.edu/lunar/lp-l-grs-5-elem-abundance-v1/ lp_9001/data/lpgrs_high1_elem_abundance_5deg.tab.

Substitution of the above iron and titanium contents $(S)$ into Eq. (17) gives $\rho_{\text {grain. }}$. Once $\rho$ and $\rho_{\text {grain }}$ are known, the porosity, $p$, can be estimated using Eq. (19). The remaining model parameters, $\sigma_{1}$ and $\varepsilon_{2}$, can be determined using
Eqs. (10), (12) and (16) in addition to observed $P_{\text {rss }}$ as shown in the flowchart (Fig. 5).

In this analysis, we need absolute values of the echo powers in unit of W. They are determined based on the prelaunch calibration of the LRS's receiver. Of course, it was not confirmed by the end-to-end calibration including extended antenna and spacecraft because such test was quite difficult to perform on the ground. So, we roughly check validity of the absolute calibration of the echo powers used in this study by comparison between bulk permittivities estimated in Ishiyama et al. (2013) and those in this study (see "Validity of applied methods" section).

\section{Results}

\section{Analyzed regions}

We analyzed four lunar maria, viz., Mare Serenitatis, Oceanus Procellarum, Mare Imbrium, and Mare Crisium. This is partly because clear subsurface reflectors were recognized by radargrams of several adjacent orbits in those lunar maria, and partly because it is difficult to completely eliminate the effect of surface echoes, which are especially intense in the highland areas of the Moon. Figure 6 shows the four target regions under study. Note that the values described in this section are mainly field estimates of bulk properties.

\section{Estimated physical properties of all maria}

Because reflected echoes from the Moon's surface were observed everywhere, the bulk permittivity of the first layer, $\varepsilon_{1}$, was estimated using Eq. (9) for 371 shots, which were approximately equivalent to one selenographic latitude. $\varepsilon_{\text {grain }}$ was estimated using Eqs. (17) and (18) together with the iron-titanium content of this region by Lawrence et al. (2002).

Unlike the surface echoes, the subsurface echoes were not always detected. To circumvent this, 21 stacks of A-scope were taken using the surface echo as a reference. Figure 7 shows an example of the stacked A-scope. Using those stacked echoes, estimates of $\varepsilon_{2}$ were obtained in the respective latitudinal ranges using the previously estimated $\varepsilon_{1}$ and Eq. (10).

Radargrams of all regions are shown in Figs. 8, 9, 10 and 11 , while estimates of $\varepsilon_{1}, \varepsilon_{2}$, and $\varepsilon_{\text {grain }}$ are plotted in Figs. 12, 13, 14 and 15 for lunar maria under study. Table 1 shows estimated porosity (\%), loss tangent, electrical conductivity $(\mathrm{S} / \mathrm{m})$ in addition to the derived relative permittivities. The $\mathrm{Fe}+\mathrm{Ti}$ content, $S$ (wt\%), tabulated in Table 1 was used to estimate $\varepsilon_{\text {grain }}$. The table also includes the averaged apparent depths $(\mathrm{m})$ as well as the calculated actual depths (m), and the number of identified subsurface echoes. In Mare Serenitatis and Oceanus Procellarum, the derived ranges of $\varepsilon_{1}$ are almost 


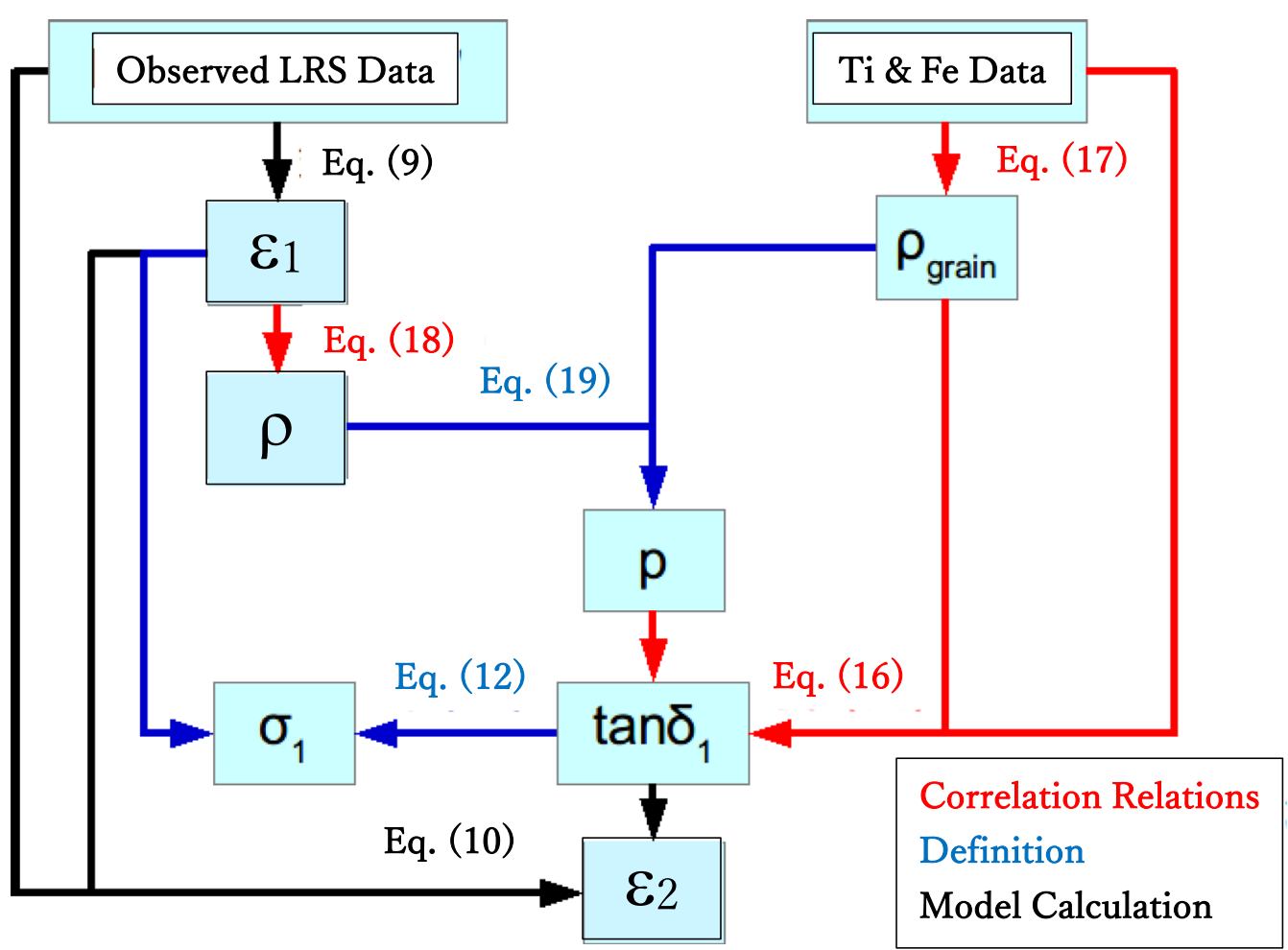

Fig. 5 The flowchart of data analysis of this study. $\rho, p$ and $\delta_{1}$ denote density, porosity and loss tangent of the 1st layer, respectively, while $\rho_{\text {grain }}$ indicates the density pertaining to the solid material itself. As for $\varepsilon_{1}, \sigma_{1}$ and $\varepsilon_{2}$, refer to the caption of Fig. 4

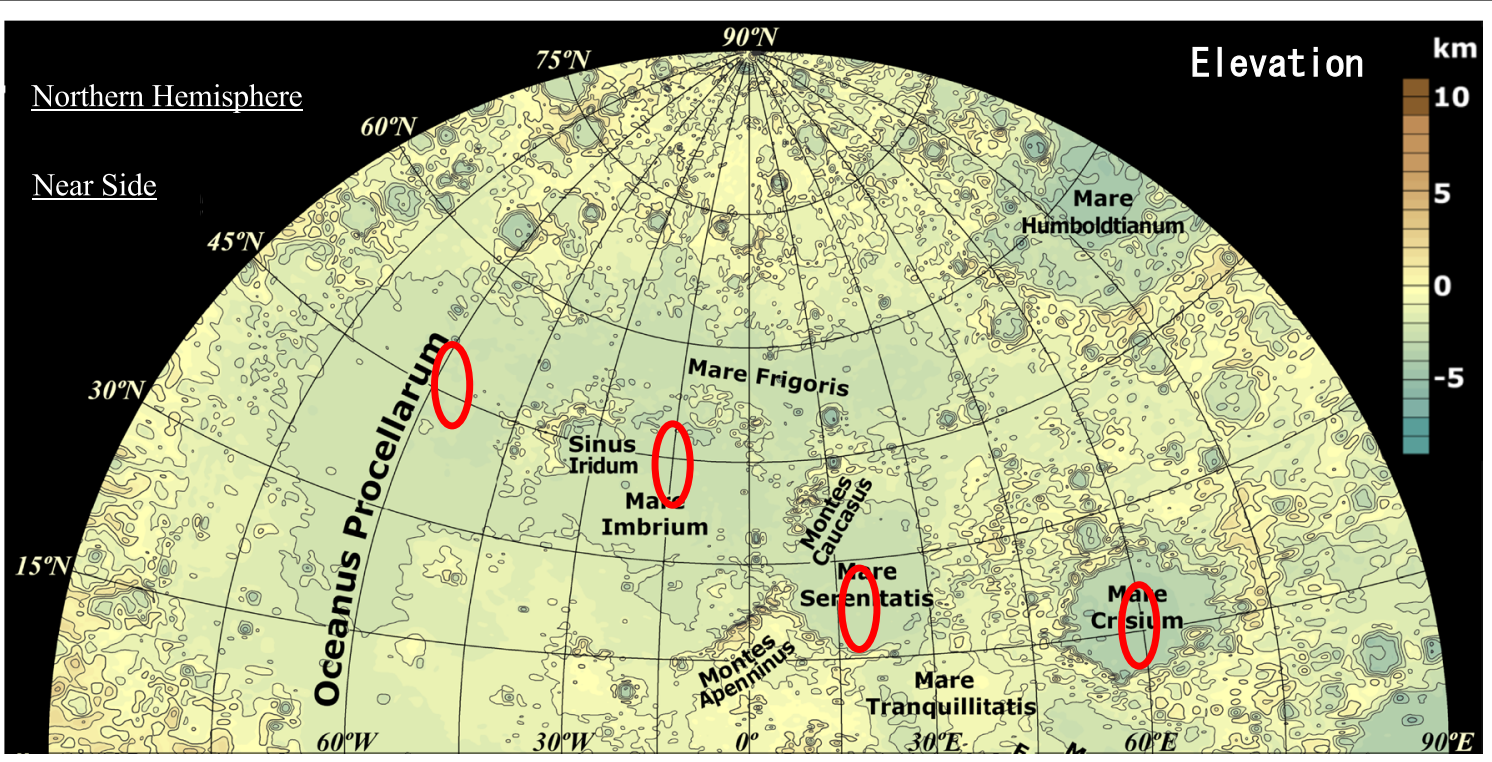

Fig. 6 The topographic map of the northern hemisphere on the near side of the Moon. The base map was downloaded from Geospatial Information Authority of Japan (http://gisstar.gsi.go.jp/selene/Maps/Stereo_En-800.tif.zip), which is jointly operated by National Astronomical Observatory of Japan and Japan Aerospace Exploration Agency. The four red ellipses denote the location of the target areas of this study 


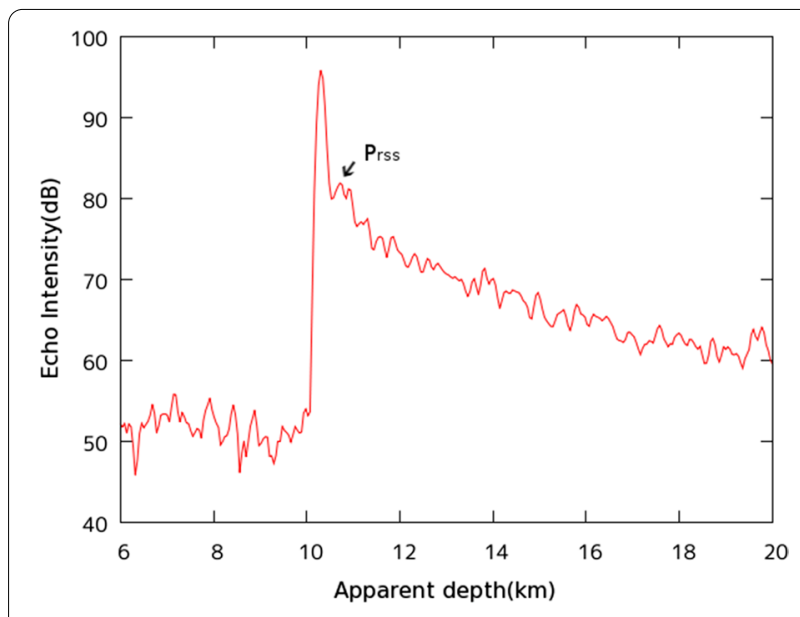

Fig. 7 The stacked A-scope. $P_{\text {rss }}$ indicates the location of the subsurface echo compatible with those reported by Ishiyama et al. (2013): $1.6-14.0$ and $1.3-5.1$.

\section{Summary of data analyses}

All results described in this section are summarized in Table 1 along with estimated ages of the lunar maria determined by crater density (Hiesinger et al., 2000; 2003; 2011). Values of the bulk permittivity show correlation with $S$. Table 1 also shows that each tabulated value has small spatial variation in the latitude difference of $5^{\circ}$ to $10^{\circ}$. Figure 16 was created from Table 1 using values of $\varepsilon_{1}$ and their 95\% confidence intervals shown in Figs. 12, 13, 14 and 15. Table 1 shows a clear positive correlation of the bulk permittivity, $\varepsilon_{1}$, derived in this study with the reported Fe and Ti content, $S$ (Lawrence et al. 2002). The bulk permittivity can be expressed by $\varepsilon_{1}=0.297$ $S+0.0107$ with a correlation coefficient of $R^{2}=0.881$.

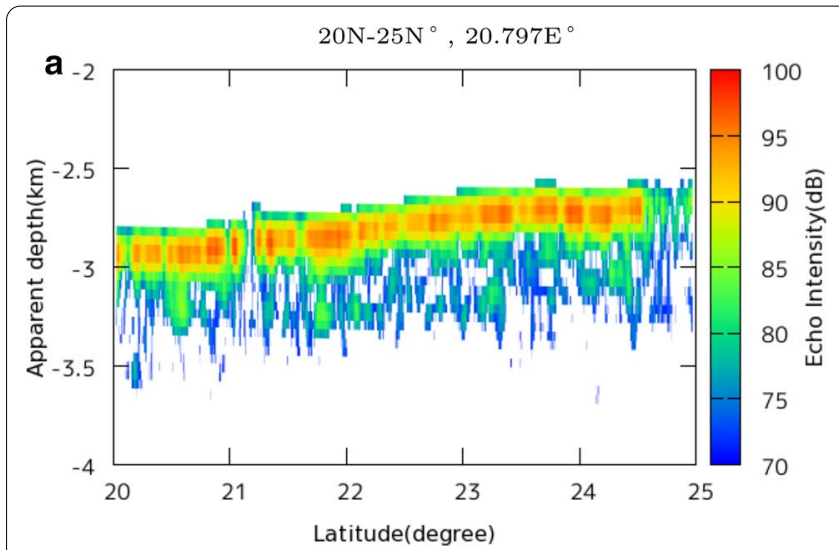

Fig. 8 Radargrams of Mare Serenitatis for a $20-25^{\circ} \mathrm{N}$ and b $25-30^{\circ} \mathrm{N}$
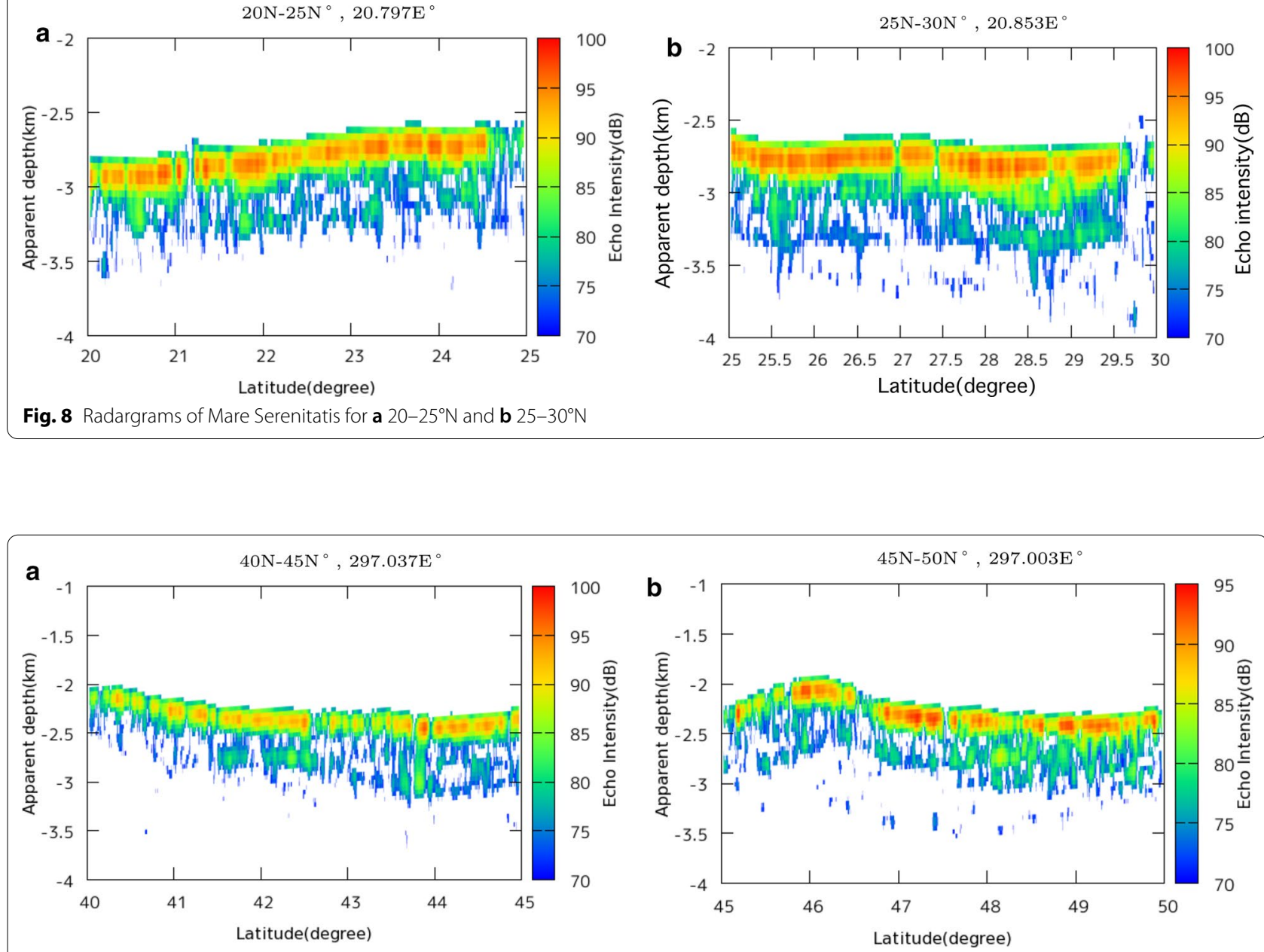

Fig. 9 Radargrams of Oceanus Procellarum for a $40-45^{\circ} \mathrm{N}$ and $\mathbf{b} 45-50^{\circ} \mathrm{N}$ 

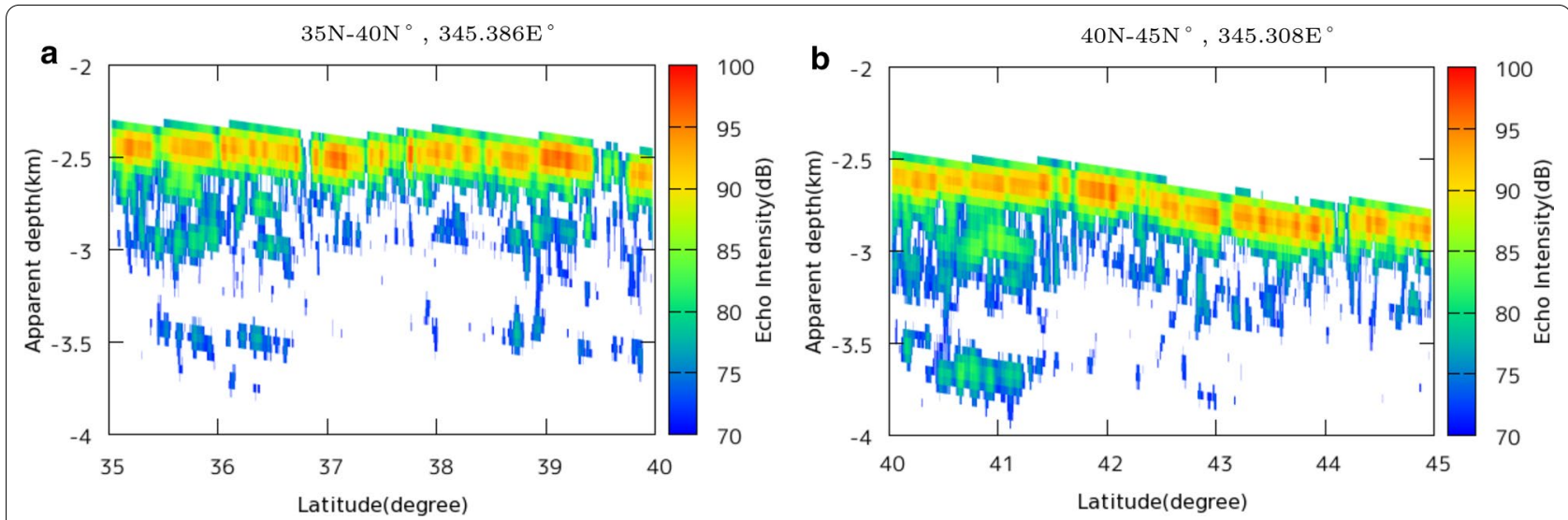

Fig. 10 Radargrams of Mare Imbrium for a $35-40^{\circ} \mathrm{N}$ and $\mathbf{b} 40-45^{\circ} \mathrm{N}$. Averaged B-scan images are plotted

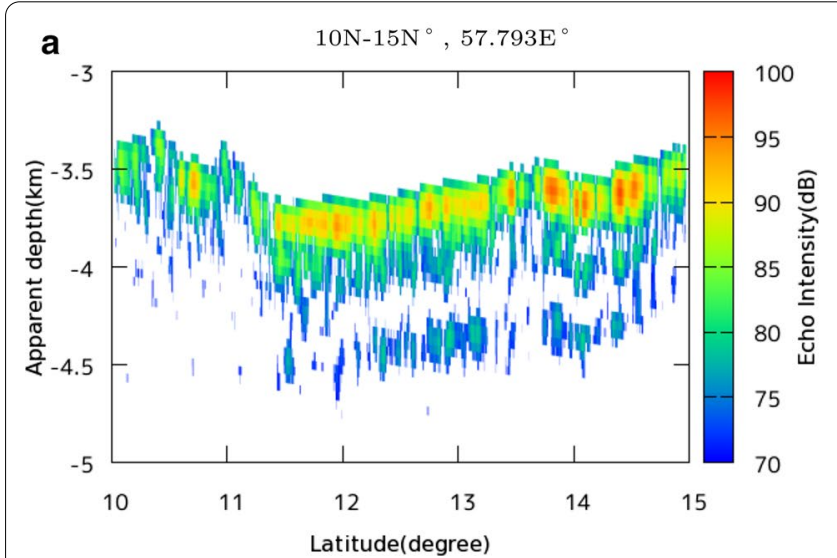

Fig. 11 Radargrams of Mare Crisium for a $10-15^{\circ} \mathrm{N}$ and $\mathbf{b} 15-20^{\circ} \mathrm{N}$

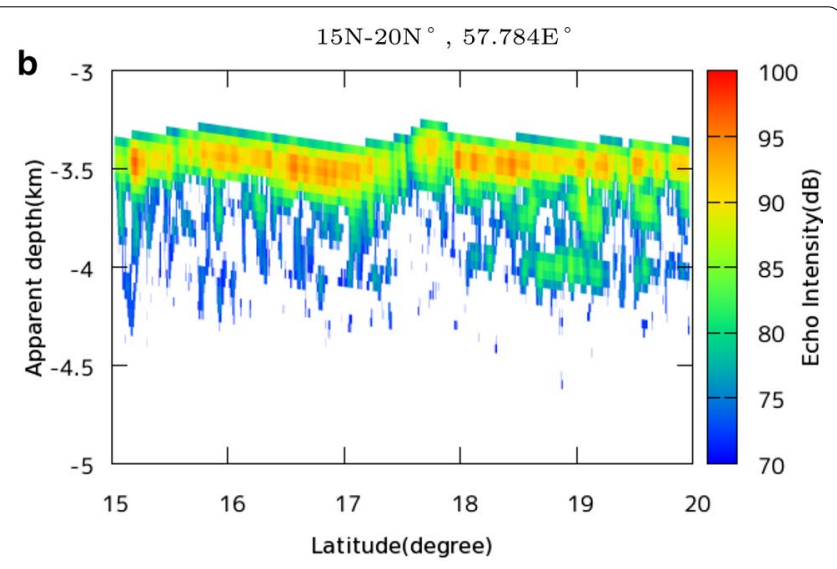

$20 \mathrm{~N}-25 \mathrm{~N}^{\circ}, 20.797 \mathrm{E}^{\circ}$

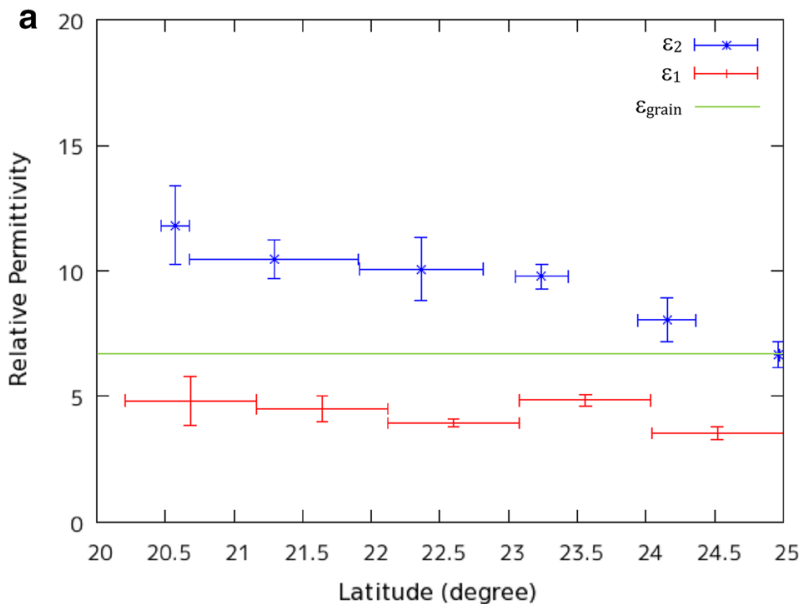

$25 \mathrm{~N}-30 \mathrm{~N}^{\circ}, 20.853 \mathrm{E}^{\circ}$

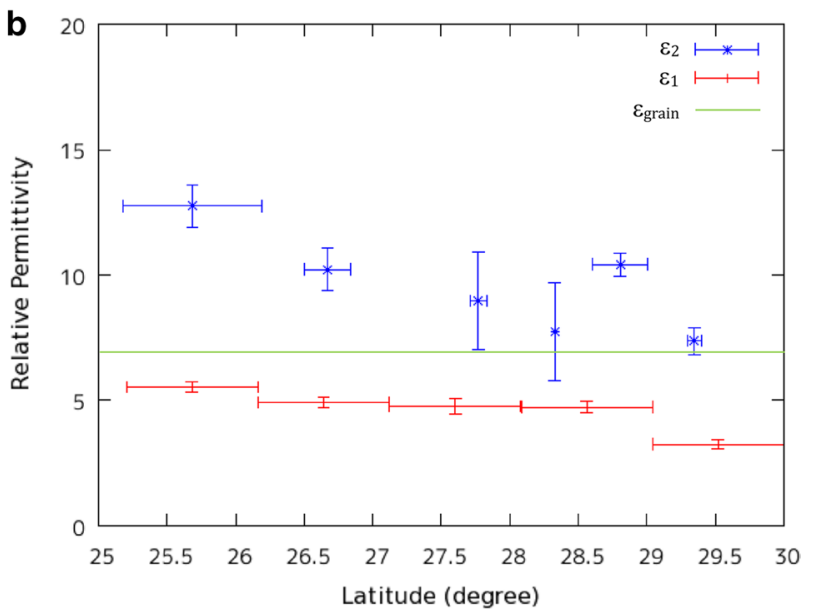

Fig. 12 Estimates of $\varepsilon_{1}$ (red), $\varepsilon_{2}$ (blue) and $\varepsilon_{\text {grain }}$ of Mare Serenitatis for $\mathbf{a} 20-25^{\circ} \mathrm{N}$ and $\mathbf{b} 25-30^{\circ} \mathrm{N}$. The regional representatives of $\varepsilon_{\text {grain }}=6.49$ (for $20-25^{\circ} \mathrm{N}$ ) and 6.39 (for $25-30^{\circ} \mathrm{N}$ ) are shown by horizontal green lines. The vertical error bars for $\varepsilon_{1}$ and $\varepsilon_{2}$ show $95 \%$ confidence intervals, while horizontal error bars denote their spatial extent 

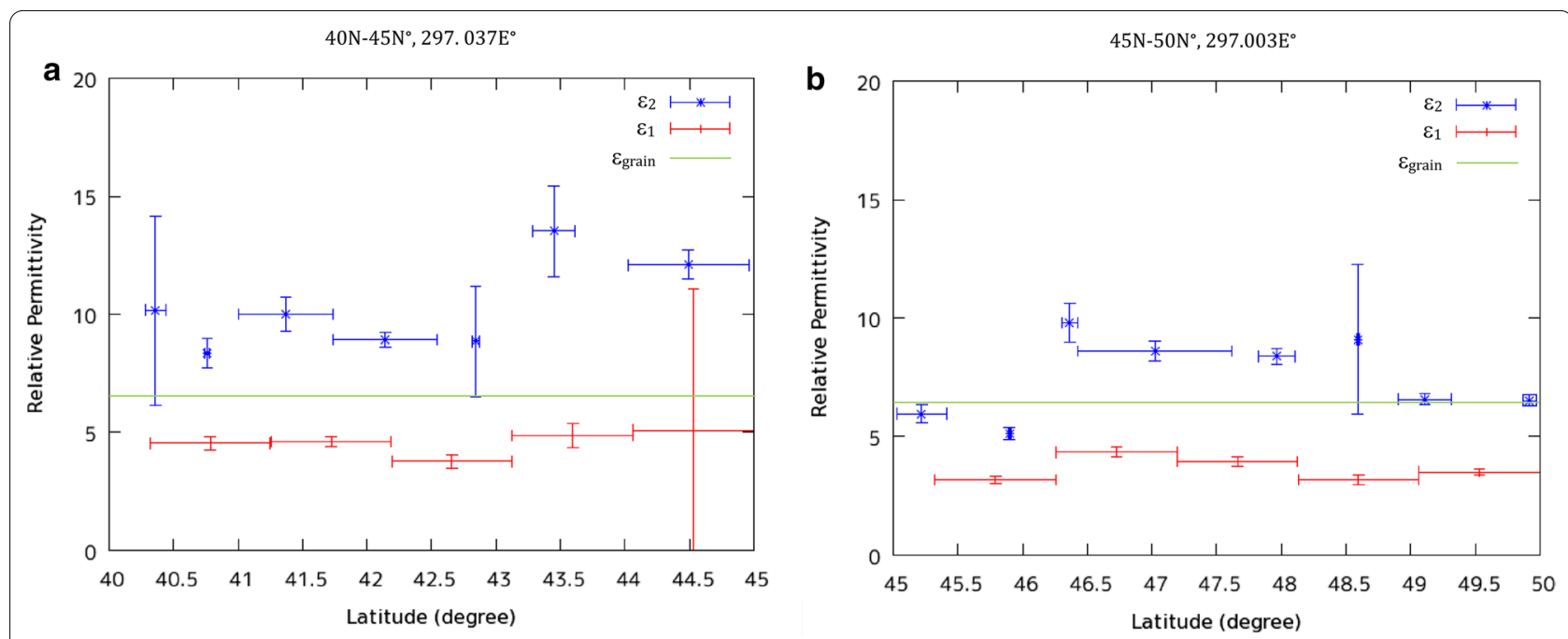

Fig. 13 Estimates of $\varepsilon_{1}(\mathrm{red}), \varepsilon_{2}$ (blue) and $\varepsilon_{\text {grain }}$ of Oceanus Procellarum for $\mathbf{a} 40-45^{\circ} \mathrm{N}$ and $\mathbf{b} 45-50^{\circ} \mathrm{N}$. The regional representatives, i.e., $\varepsilon_{\text {grain }}=6.41$ (for $40-45^{\circ} \mathrm{N}$ ) and 6.29 (for $45-50^{\circ} \mathrm{N}$ ) are shown by horizontal green lines. The vertical error bars for $\varepsilon_{1}$ and $\varepsilon_{2}$ show $95 \%$ confidence intervals, while horizontal error bars denote their spatial extent

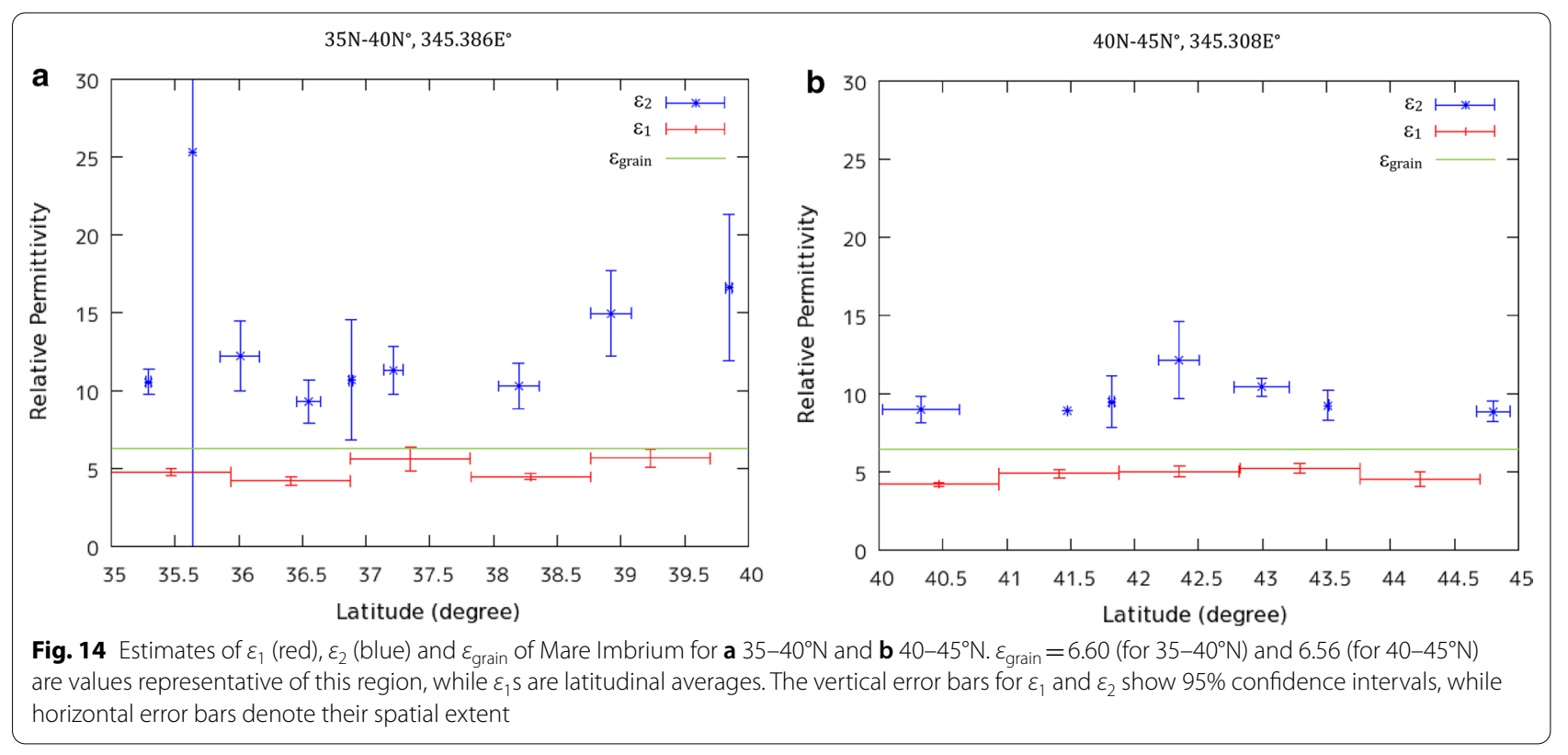

\section{Discussion}

\section{Validity of applied methods}

Because many of A-scope data showed peaks of a single subsurface reflector that can be identified on adjacent orbits as well, it is reasonable to assume two-layer models for the LRS data. However, the analyzed results show that there are several regions of anomalously large errors for bulk permittivity. It is very difficult to consider those errors due to actual spatial variations of $\varepsilon_{1}$ and $\varepsilon_{2}$. It can be rather interpreted as a result of scattering of surface echoes by rugged topography. The radargrams over the large error regions suggest that those regions are characterized by combinations of intense and weak echoes. In this study, relatively flat regions were selected to yield radargrams by taking running means for better protection against rugged topography. However, the results showed that it is not sufficient for all regions. It, therefore, will be desirable to do more accurate numerical simulations of EM wave propagation by incorporating known topography on the Moon's surface, to estimate more precise bulk permittivity over broader regions in the future. As confirmed in Subsections "Estimated 


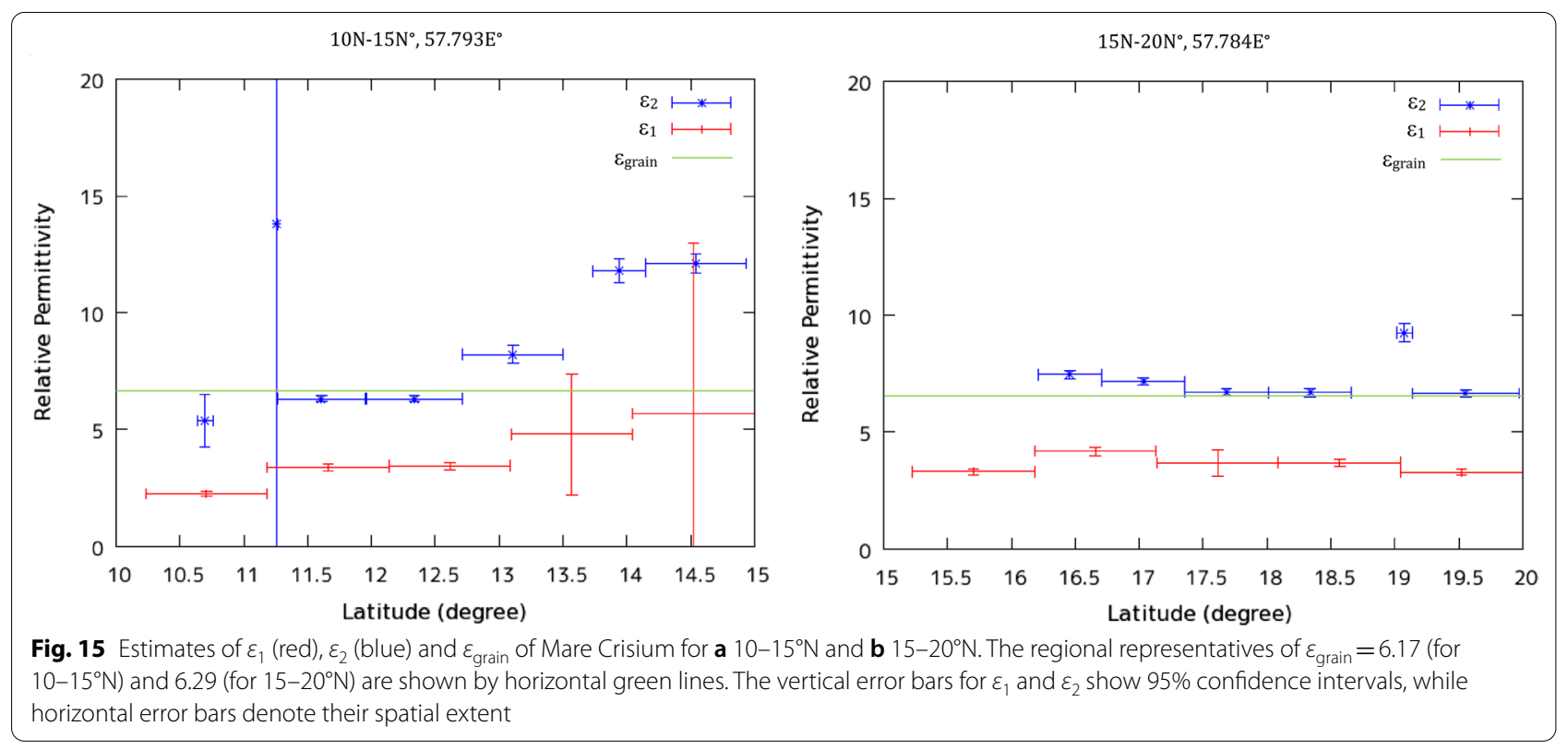

Table 1 Summary of the data analysis

\begin{tabular}{|c|c|c|c|c|c|c|c|c|}
\hline \multirow[b]{2}{*}{$\begin{array}{l}\text { Latitude } \\
\text { Longitude }\end{array}$} & \multicolumn{2}{|c|}{ Mare Imbrium } & \multicolumn{2}{|c|}{ Oceanus Procellarum } & \multicolumn{2}{|c|}{ Mare Crisium } & \multicolumn{2}{|l|}{ Mare Serenitatis } \\
\hline & $\begin{array}{l}35-40^{\circ} \mathrm{N} \\
345.386 \mathrm{E}\end{array}$ & $\begin{array}{l}40-45^{\circ} \mathrm{N} \\
345.308 \mathrm{E}\end{array}$ & $\begin{array}{l}40-45^{\circ} \mathrm{N} \\
297.037 \mathrm{E}\end{array}$ & $\begin{array}{l}45-50^{\circ} \mathrm{N} \\
297.003 \mathrm{E}\end{array}$ & $\begin{array}{l}10-15^{\circ} \mathrm{N} \\
57.793 \mathrm{E}\end{array}$ & $\begin{array}{l}15-20^{\circ} \mathrm{N} \\
57.784 \mathrm{E}\end{array}$ & $\begin{array}{l}20-25^{\circ} \mathrm{N} \\
20.797 \mathrm{E}\end{array}$ & $\begin{array}{l}25-30^{\circ} \mathrm{N} \\
20.853 \mathrm{E}\end{array}$ \\
\hline Age (100 Ma) & 35.2 & & 34.4 & & 35.0 & & 34.9 & \\
\hline $\mathrm{S}(\mathrm{Fe}+\mathrm{Ti} w \mathrm{w} \%)$ & 16.86 & 16.31 & 14.26 & 12.41 & 10.61 & 12.50 & 15.36 & 13.95 \\
\hline$\varepsilon_{1}$ & $3.91-6.37^{\mathrm{a}}$ & $4.04-5.53$ & $3.49-5.38^{b}$ & $2.96-4.54$ & $3.23-3.60^{c}$ & $3.15-4.37$ & $3.29-5.81$ & $3.06-5.74$ \\
\hline$\varepsilon_{\text {grain }}$ & 6.60 & 6.56 & 6.41 & 6.29 & 6.17 & 6.29 & 6.49 & 6.39 \\
\hline Apparent depth (m) & 500 & & 400 & & 300 & & 350 & \\
\hline Actual depth (m) & $198-253$ & $213-249$ & $172-214$ & $188-233$ & $158-167$ & $143-169$ & $145-193$ & $146-200$ \\
\hline$p(\%)$ & $1.8-27.8$ & $9.1-25.7$ & $9.5-32.8$ & $17.7-41.1$ & $29.6-35.6$ & $19.8-37.7$ & $6.0-36.4$ & $5.8-39.6$ \\
\hline $\tan \delta 1\left(\times 10^{-2}\right)$ & $1.05-1.53$ & $1.03-1.31$ & $0.77-1.07$ & $0.58-0.81$ & $0.53-0.58$ & $0.61-0.79$ & $0.81-1.25$ & $0.68-1.10$ \\
\hline$\sigma 1\left(\times 10^{-5} \mathrm{~S} / \mathrm{m}\right)$ & $1.14-2.71$ & $1.16-2.01$ & $0.75-1.61$ & $0.48-1.02$ & $0.48-0.58$ & $0.54-0.96$ & $0.74-2.02$ & $0.58-1.76$ \\
\hline$\varepsilon_{2}$ & $6.81-21.28$ & $7.81-14.61$ & $6.17-15.44$ & $4.84-12.26$ & $4.25-12.52^{d}$ & $6.55-9.63$ & $6.13-13.35$ & $5.78-13.59$ \\
\hline \# of subsurface echoes & 221 & 162 & 586 & 427 & 1025 & 1274 & 634 & 345 \\
\hline
\end{tabular}

${ }^{a}$ We eliminated the value at $35.6^{\circ} \mathrm{N}$ due to its large error bar

${ }^{b}$ We excluded an outlier at $44.5^{\circ} \mathrm{N}$

c Values with large error bars at $13.5^{\circ}$ and $14.5^{\circ} \mathrm{N}$ as well as subject to topographic effect at $10.7^{\circ} \mathrm{N}$ were not included

${ }^{\mathrm{d}}$ A value at $11.3^{\circ} \mathrm{N}$ was not adopted due to its large estimated error

physical properties of all maria" and "Summary of data analyses", the bulk permittivities derived in Mare Serenitatis and Oceanus Procellarum in this study were almost in the range reported in Ishiyama et al. (2013).

\section{Bulk permittivity}

The derived bulk permittivity of the lunar uppermost layer was in a range from 2.96 (at Mare Imbrium) to 6.37 (at Oceanus Procellarum), which supports the actual depth to the reflectors in those maria to be around $200 \mathrm{~m}$.
Olhoeft and Strangway (1975), and Carrier et al. (1991) reported that the bulk permittivity of the Moon rock samples shows values ranging from 1.1 to 11 , majority of which falls between 4 and 9 . However, this study yields somewhat smaller bulk permittivity not only in Mare Serenitatis and Oceanus Procellarum, which was already reported by Ishiyama et al. (2013), but also in Mare Imbrium and Mare Crisium. This can be partly attributed to the effect of porosity as discussed by Ishiyama et al. (2013), but also explained by the effect of composition, i.e., iron-titanium content. 


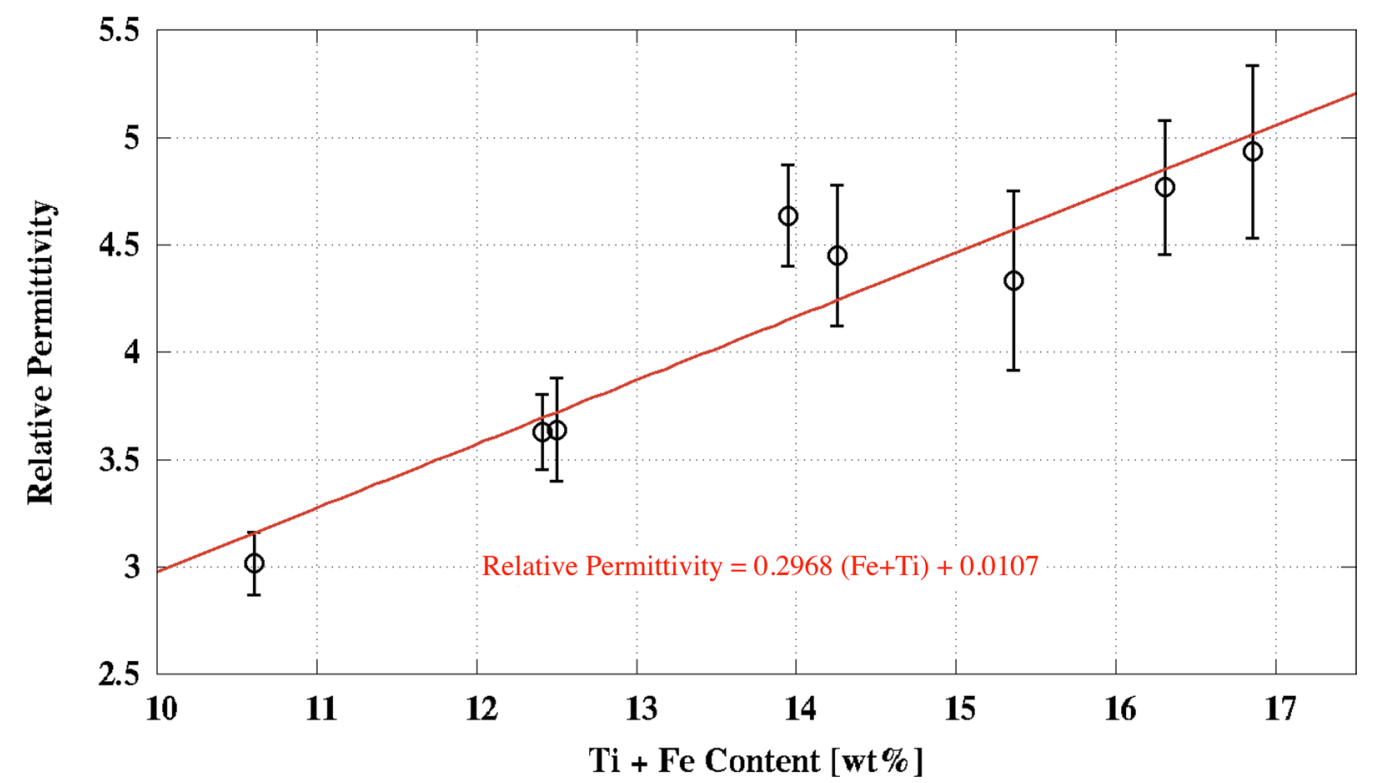

Fig. 16 Correlation between the bulk permittivity of the 1 st layer, $\varepsilon_{1}$, and the surface metal content in lunar maria under study. A regression line is drawn in red. The error bars of $\varepsilon_{1}$ were calculated using values of $\varepsilon_{1}$ and their $95 \%$ confidence intervals shown in Figs. 12, 13,14 and 15

Olhoeft and Strangway (1975) showed that the bulk permittivity is primarily a strong function of bulk density. This means that the bulk permittivity depends on not only how porous the medium in concern is, but also how dense and dielectric the rest of the medium other than cavity is. Titanium bearing minerals such as ilmenite is typical of those that have both large density and high permittivity. The good correlation between the bulk permittivity derived in this study and the known $\mathrm{FeO}+\mathrm{TiO}_{2}$ content of the lunar maria surface shown in Fig. 16 can be regarded as possible presence of enriched titanium bearing minerals in each lunar mare such as Mare Imbrium.

The analysis method used in this study enabled us to derive bulk permittivity and porosity in wide area of multiple maria. A new suggestion brought by the comparison of porosity in multiple maria in this study will be described in the next subsection. The estimates of $\varepsilon_{2}$ showed larger shot-by-shot scatter than $\varepsilon_{1}$. It was assumed throughout this study that $\varepsilon_{1}<\varepsilon_{2}$ in applying the two-layer models. However, its validity for multiple layer models should be examined in the future.

\section{Porosity}

Based on the bulk permittivity from 2.96 to 6.37 , the porosity takes the values between 1.8 and $41.1 \%$. Porosity of the Moon rock samples is less than $10 \%$ in most cases, and hence samples with porosity larger than $20 \%$ are rare (Olhoeft and Strangway 1975). However, this study yielded larger porosity, which possibly represents macroscopic (bulk) porosity rather than microscopic as was pointed out by Ishiyama et al. (2013).

Sizes of the Moon rock samples are of the order of centimeter, while the spatial resolution of LRS is at most a few tens of meters. This means that the LRS data are subject to effects of large-scale cracks. Hence, the large bulk porosity may be due to cracks by degassing at the time of volcanic eruptions, by quenching of lavas or by meteorite impacts. However, it turned out that porosity shows a weak negative correlation with formation ages of lunar maria (see Fig. 17). This may reflect effects of volcanic eruptions rather than those of meteorite impacts, because repeated meteorite impacts might have cultivated the Moon's surface well enough to give a 'positive' correlation with formation age.

\section{Loss tangent}

The estimated range of loss tangent was $5.3 \times 10^{-3}$ $1.53 \times 10^{-2}$ in this study. Olhoeft and Strangway (1975) derived a range of $7.53 \times 10^{-3}-1.92 \times 10^{-2}$ at $(\mathrm{Fe}+\mathrm{Ti}$ $\mathrm{wt} \%)=15$ by their laboratory experiments of the Moon rock samples. The smaller loss tangent range of this study may also be attributed to the macroscopic porosity. Substitution of $(\mathrm{Fe}+\mathrm{Ti} \mathrm{wt} \%)=15$ into Eqs. (16) and (17) yields a width of $4.6 \times 10^{-3}$ for the loss tangent range, if porosity is changed from $0 \%$ through $30 \%$. If the observed loss tangent is corrected by this range width, the two ranges, i.e., the field and laboratory ranges, agree very well. Furthermore, Bando et al. (2015) investigated the ratio between the powers of echoes from subsurface 


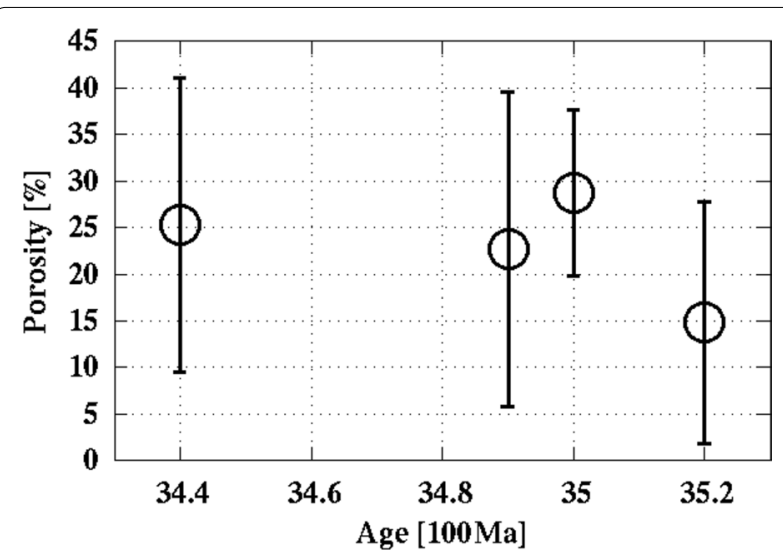

Fig. 17 Correlation between the bulk porosity of the 1st layer, $\rho$, and the formation age of each lunar mare under study

reflectors at different depths measured by LRS to yield a loss tangent range of $1.07 \times 10^{-2}-1.13 \times 10^{-2}$, which corresponds to the median value of the observed loss tangent by this study. It, therefore, can be concluded that the loss tangent by this study may reflect the true loss tangent near the lunar surface (10-100 m spatial scale) with possible variations produced by macroscopic porosity.

\section{Conclusions}

Assuming incident EM waves from LRS being normal to the horizontally stratified two-layer models, bulk permittivity, porosity and loss tangent near the lunar surface were estimated using the observed LRS data by calculating EM wave propagation according to the radar range equation. Combined use of the estimated $\mathrm{FeO}+\mathrm{TiO}_{2}$ content distribution by spectroscopy of the lunar surface (Lawrence et al. 2002) and the empirical relations among physical quantities in concern derived from analyses of the Moon rock samples (Shkuratov and Bondarenko 2001; Olhoeft and Strangway 1975) enabled unique determination of otherwise degenerated physical quantities. The results are summarized in Table 1 , in which all the analyzed regions, viz., Mare Imbrium, Oceanus Procellarum, Mare Crisium and Mare Serenitatis, are included. It is obvious by the table that the actual depth to the subsurface reflectors of the Moon is around $200 \mathrm{~m}$ except for Mare Crisium and one part of Mare Serenitatis.

The estimates of each physical quantity do not change much within a latitudinal difference of $5^{\circ}$ to $10^{\circ}$, whereas bulk permittivity shows a positive correlation with $\mathrm{FeO}+\mathrm{TiO}_{2}$ content. Since porosity, in turn, shows a weak negative correlation with formation ages of lunar maria (see Fig. 17), it may reflect effects of volcanic eruptions rather than those of meteorite impacts. Finally, Table 1 will make a good reference for future studies, because discrepancy between the field and laboratory estimates turned out to be reconciled by the effect of porosity.

\section{Abbreviations}

ALSE: Apollo Lunar Sounder Experiment; EM: Electromagnetic; ESA: European Space Agency; JUICE: JUpiter ICy moon Explorer; LRS: Lunar Radar Sounder; RIME: Radar of Icy Moon Exploration; SELENE: SELenological and ENgineering Explorer.

\section{Acknowledgements}

We are indebted to Professors A. Yamaji at Graduate School of Science, Kyoto University, and M. Yamamoto at Research Institute for Sustainable Humanosphere, Kyoto University, for their help that was indispensable to complete this work.

\section{Authors' contributions}

$\mathrm{KH}$ carried out data processing, modelling and figure and table drawings. $\mathrm{HT}$ supervised $\mathrm{KH}$ throughout this study to achieve a master degree, and converted his master thesis in Japanese to the draft manuscript in English. AK guided the data processing and modelling by providing raw time-series of reflected echoes together with their metadata and necessary information for modelling/interpretation. All authors read and approved the final manuscript.

\section{Funding}

This work was partly supported by JSPS KAKENHI Grant Numbers JP25420402 and 19 K03993.

\section{Availability of data and materials}

The datasets used and/or analyzed during the current study are available from the following links: The LRS data: http:///2db.selene.darts.isas.jaxa.jp/. The Fe and Ti content distribution: http://www.mapaplanet.org/data_local/ Lunar_Prospector/lp_fe_5d.asc. http://www.mapaplanet.org/data_local/Lunar _Prospector/Ip_ti_5d.asc

\section{Competing interests}

The authors declare that they have no competing interests.

\section{Author details}

${ }^{1}$ Division of Earth and Planetary Sciences, Graduate School of Science, Kyoto University, Kyoto, Japan. ${ }^{2}$ Department of Geophysics, Graduate School of Science, Tohoku University, Sendai, Japan.

Received: 30 March 2020 Accepted: 25 August 2020

Published online: 22 September 2020

\section{References}

Bando Y, Kumamoto A, Nakamura N (2015) Constraint on subsurface structures beneath Reiner Gamma on the moon using the KAGUYA lunar radar sounder. Icarus 254:144-149

Carrier WD, Olhoeft GR, Mendell W (1991) Physical properties of the lunar surface. Lunar Sourcebook, pp 475-594

De Hon RA (1979) Thickness of the western mare basalts. In: Lunar and planetary science conference proceedings, vol. 10, pp 2935-2955

ESA/SRE (2014) JUICE definition study report (red book)

Hiesinger H, Jaumann R, Neukum G, Head JW (2000) Ages of mare basalts on the lunar nearside. J Geophys Res 105(E12):29239-29275

Hiesinger H, Head J, Wolf U, Jaumann R, Neukum G (2003) Ages and stratigraphy of mare basalts in Oceanus Procellarum, Mare Nubium, Mare Cognitum, and Mare Insularum. J Geophys Res 108(E7):5065. https://doi. org/10.1029/2002JE001985

Hiesinger H, Bogert C, van der Reiss D, Robinson M (2011) Absolute model ages of basalts in Mare Crisium. In: EPSC-DPS joint meeting 2011, vol 1, pp 1095

Holt J, Fishbaugh K, Byrne S, Christian S, Tanaka K, Russell P, Herkenhoff K, Safaeinili A, Putzig N, Phillips R (2010) The construction of Chasma Boreale on mars. Nature 465(7297):446-449 
Ishiyama K, Kumamoto A, Ono T, Yamaguchi Y, Haruyama J, Ohtake M, Katoh Y, Terada N, Oshigami S (2013) Estimation of the permittivity and porosity of the lunar uppermost basalt layer based on observations of impact craters by SELENE. J Geophys Res 118(7):1453-1467

Karlsson N, Schmidt L, Hvidberg C (2015) Volume of Martian midlatitude glaciers from radar observations and ice flow modeling. Geophys Res Lett 42(8):2627-2633

Kato M, Sasaki S, Tanaka K, lijima Y, Takizawa Y (2008) The Japanese lunar mission SELENE: science goals and present status. Adv Space Res 42(2):294300. https://doi.org/10.1016/j.asr.2007.03.049

Kobayashi T, Ono T (2007) Sar/insar observation by an HF sounder. J Geophys Res. 112:E3

Kobayashi T, Kim J-H, Lee SR, Kumamoto A, Nakagawa H, Oshigami S, Oya H, Yamaguchi Y, Yamaji A, Ono T (2012) Synthetic aperture radar processing of KAGUYA lunar radar sounder data for lunar subsurface imaging. IEEE Trans Geosci Remote Sens 50(6):2161-2174

Lawrence JD, Feldman WC, Elphic RC, Little R, Prettyman T, Maurice S, Lucey PG, Binder AB (2002) Iron abundaces on the lunar surface as measured by the Lunar Prospector gamma-ray and neutron spectrometers. J Geophys Res. https://doi.org/10.1029/2001je001530

Olhoeft GR, Strangway D (1975) Dielectric properties of the first 100 meters of the moon. Earth Planet Sci Lett 24:394-404

Ono T, Oya H (2000) Lunar radar sounder (LRS) experiment on-board the SELENE spacecraft. Earth Planets Space 52(9):629-637

Ono T, Kumamoto A, Yamaguchi Y, Yamaji A, Kobayashi T, Kasahara Y, Oya H (2008) Instrumentation and observation target of the lunar radar sounder (LRS) experiment on-board the SELENE spacecraft. Earth Planets Space 60(4):321-332

Ono T, Kumamoto A, Nakagawa H, Yamaguchi Y, Oshigami S, Yamaji A, Kobayashi T, Kasahara Y, Oya H (2009) Lunar radar sounder observations of subsurface layers under the nearside maria of the moon. Science 323(5916):909-912

Ono T, Kumamoto A, Kasahara Y, Yamaguchi Y, Yamaji A, Kobayashi T, Oshigami S, Nakagawa H, Goto Y, Hashimoto K et al (2010) The lunar radar sounder (LRS) onboard the KAGUYA (SELENE) spacecraft. Space Sci Rev 154(1-4):145-192
Oshigami S, Yamaguchi Y, Yamaji A, Ono T, Kumamoto A, Kobayashi T, Nakagawa $\mathrm{H}$ (2009) Distribution of the subsurface reflectors of the western nearside maria observed from KAGUYA with lunar radar sounder. Geophys Res Lett 36:18

Peeples WJ, Sill WR, May TW, Ward SH, Phillips RJ, Jordan RL, Abbott EA, Killpack TJ (1978) Orbital radar evidence for lunar subsurface layering in Maria Serenitatis and Crisium. J Geophys Res 83(B7):3459-3468

Phillips R, Adams G, Brown Jr W, Eggleton R, Jackson P, Jordan R, Linlor W, Peeples W, Porcello L, Ryu J et al (1973a) Apollo lunar sounder experiment. In: Apollo 17 preliminary science report (NASA SP-330), pp 1-26

Phillips R, Adams G, Brown Jr W, Eggleton R, Jackson P, Jordan R, Peeples W, Porcello L, Ryu J, Schaber G et al (1973b) The apollo 17 lunar sounder. In: Lunar and planetary science conference proceedings, vol 4, p 2821

Picardi G, Plaut JJ, Biccari D, Bombaci O, Calabrese D, Cartacci M, Cicchetti A, Clifford SM, Edenhofer P, Farrell WM et al (2005) Radar soundings of the subsurface of Mars. Science 310(5756):1925-1928

Plaut JJ, Picardi G, Safaeinili A, Ivanov AB, Milkovich SM, Cicchetti A, Kofman W, Mouginot J, Farrell WM, Phillips RJ et al (2007) Subsurface radar sounding of the south polar layered deposits of Mars. Science 316(5821):92-95

Pommerol A, Kofman W, Audouard J, Grima C, Beck P, Mouginot J, Herique A, Kumamoto A, Kobayashi T, Ono T (2010) Detectability of subsurface interfaces in lunar maria by the LRS/SELENE sounding radar: Influence of mineralogical composition. Geophys Res Lett 37:3

Porcello $\sqcup$ et al (1974) The Apollo lunar sounder radar system. Proc IEEE 62(6):769-783. https://doi.org/10.1109/PROC.1974.9517

Rust A, Russell J, Knight R (1999) Dielectric constant as a predictor of porosity in dry volcanic rocks. JVolcanol Geoth Res 91(1):79-96

Shkuratov YG, Bondarenko NV (2001) Regolith layer thickness mapping of the moon by radar and optical data. Icarus 149:329-338

Williams KK, Zuber MT (1998) Measurement and analysis of lunar basin depths from clementine altimetry. Icarus 131(1):107-122

\section{Publisher's Note}

Springer Nature remains neutral with regard to jurisdictional claims in published maps and institutional affiliations.

\section{Submit your manuscript to a SpringerOpen ${ }^{\circ}$ journal and benefit from:}

- Convenient online submission

- Rigorous peer review

- Open access: articles freely available online

- High visibility within the field

- Retaining the copyright to your article

Submit your next manuscript at $\boldsymbol{\nabla}$ springeropen.com 